\title{
C-19393 $\mathrm{S}_{2}$ AND $\mathrm{H}_{2}$, NEW CARBAPENEM ANTIBIOTICS
}

\section{TAXONOMY OF THE PRODUCING STRAIN, FERMENTATION AND ANTIBACTERIAL PROPERTIES}

\author{
Akira Imada, Yukimasa Nozaki, Kazuhiko Kintaka, Kenji Okonogi, \\ Kazuaki Kitano and Setsuo Harada \\ Microbiological Research Laboratories, Central Research Division \\ Takeda Chemical Ind. Ltd., Yodogawa-ku, Osaka 532, Japan \\ (Received for publication October 6, 1980)
}

\begin{abstract}
C-19393 $\mathrm{S}_{2}$ and $\mathrm{H}_{2}$ are new carbapenem antibiotics produced by a streptomycete. The producing strain was taxonomically studied and named Streptomyces griseus subsp. cryophilus. Cobaltous compounds were necessary for production of the antibiotics. C-19393 $\mathrm{S}_{2}$ and $\mathrm{H}_{2}$ showed a broad spectrum of antibacterial activities with $\mathrm{C}-19393 \mathrm{H}_{2}$ being $8 \sim 120$ times more active than $\mathrm{C}-19393 \mathrm{~S}_{2}$. They also exhibited $\beta$-lactamase-inhibiting activities and acted synergistically with ampicillin and cefotiam against clinical isolates resistant to $\beta$-lactam antibiotics.
\end{abstract}

We have developed a sensitive and selective screening system for finding $\beta$-lactam antibiotics in which a mutant of Pseudomonas aeruginosa $\mathrm{PsC}^{\mathrm{ss}}$ is employed as a test organism and penicillinase and cephalosporinase as discriminating probes ${ }^{1)}$. We have added, as a test organism, a mutant of Escherichia coli which lacks chromosomal $\beta$-lactamase and the penicillin-binding protein $1 \mathrm{~B}$ and is consequently hypersensitive to $\beta$-lactam antibiotics ${ }^{2}$. We have screened for $\beta$-lactam antibiotics with the above agents and encountered a streptomycete, No. C-19393, that produces new $\beta$-lactam antibiotics. The present report describes the taxonomic characterization of the producing strain as well as the fermentation and the antibacterial activities of these new antibiotics. The synergistic effect of C-19393 $\mathrm{S}_{2}$ and $\mathrm{H}_{2}$ with common $\beta$-lactam antibiotics is also described. Chemical studies which will be reported separately established their carbapenem structures shown in Fig. $1^{3)}$. Studies elucidating their modes of action ${ }^{4)}$ and mechanisms of $\beta$ lactamase inhibition ${ }^{5)}$ will be reported in forthcoming issues.

Fig. 1. Structures of antibiotics C-19393 $\mathrm{S}_{2}$ and $\mathrm{H}_{2}$.

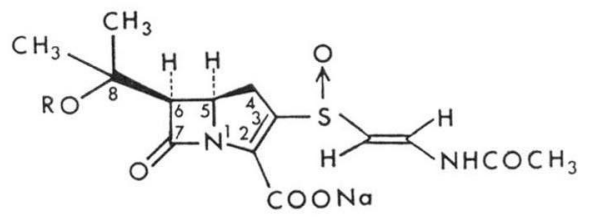

$$
\mathrm{C}-19393 \mathrm{~S}_{2}: \mathrm{R}=\mathrm{SO}_{3} \mathrm{Na}
$$$$
\text { C-19393 } \mathrm{H}_{2}: \mathrm{R}=\mathrm{H}
$$

\section{Materials and Methods}

\section{Microorganisms}

Strain No. C-19393 was isolated from a soil sample collected in Sweden and maintained on T-agar slants. Organisms used to test for antimicrobial activities are the stock cultures maintained at our laboratories. Type and authentic cultures of Streptomyces were obtained from the Institute for Fermentation, Osaka.

Media

Media used for taxonomic studies were prepared as recommended by the International Streptomyces 
Project (ISP) $)^{6)}$. T agar, which was used additionally for characterization and for the maintenance of strain No. C-19393, was prepared as follows: Twenty grams each of oatmeal and tomato paste, and $2 \mathrm{~g}$ of Bovril (edible beef extract, Bovril Ltd., Burton-on-Trent) were boiled for 10 minutes in 1 liter of tap water and the mixture was filtered through gauze. The filtrate was adjusted to $\mathrm{pH} 7.0$, made to 1 liter with tap water and supplemented with $20 \mathrm{~g}$ of Bacto agar (Difco Labs., Detroit). Agar slants were prepared after autoclaving at $120^{\circ} \mathrm{C}$ for 15 minutes.

Seed medium used for fermentation contained (g/liter): glucose 20, soluble starch 30, soybean flour 10, corn-steep liquor 10, Polypepton (Daigo Nutritive Chem., Osaka) 5, $\mathrm{NaCl} 3$, and $\mathrm{CaCO}_{3}$ (precipitated) 5. Fermentation medium contained (g/liter): glucose 30, soluble starch 30 , soybean meal 15 , cotton-seed meal 15, $\mathrm{K}_{2} \mathrm{HPO}_{4} 0.6, \mathrm{KH}_{2} \mathrm{PO}_{4} 0.25, \mathrm{CoCl}_{2} 0.002$, and Actcol (antifoam, Takeda Chem. Ind., Osaka) 0.5. The $\mathrm{pH}$ of the seed and fermentation media was adjusted to $\mathrm{pH} 7.0$ with $2 \mathrm{~N} \mathrm{NaOH}$ before sterilization.

\section{Assay methods}

Antibiotics C-19393 $\mathrm{S}_{2}$ and $\mathrm{H}_{2}$ were assayed by determining (1) antibacterial activity against mutants of Escherichia coli lacking chromosomal $\beta$-lactamase and penicillin-binding protein $1 \mathrm{~B}^{2)}$ and (2) $\beta$ lactamase-inhibiting activity using Klebsiella pneumoniae as described by Brown et al. ${ }^{7)}$ The minimum inhibitory concentrations were assayed by the conventional agar-dilution method using the medium described previously ${ }^{8)}$. The synergistic action of C-19393 $\mathrm{S}_{2}$ and $\mathrm{H}_{2}$ with ampicillin and cefotiam was examined by the two-fold agar-dilution method using Trypticase soy agar (BBL, Baltimore).

\section{Chemicals}

Ampicillin is a product of our company. Cephaloridine is a product of Eli Lilly \& Co. Cefotiam was prepared in our research division. Other chemicals are commercial products.

\section{Results}

Taxonomy of Strain No. C-19393

The taxonomic characterization was carried out according to the method recommended by the ISP ${ }^{0)}$. Unless otherwise specified, the cultivation temperature was $28^{\circ} \mathrm{C}$.

Morphological characterization

The strain produced aerial mycelium with tufts of straight to slightly wavy spore chains; it therefore belongs to the Section Rectus-Flexibilis (RF). The mature spore chains were generally long with more than 30 spores per chain. The spores were cylindrical $(0.35 \sim 0.55 \times 0.7 \sim 1.4 \mu \mathrm{m})$ and their surfaces were smooth (Fig. 2).

\section{Cultural characteristics}

The cultural characteristics observed after a 2-weeks cultivation are shown in Table 1. The strain gave the most characteristic appearance on $\mathrm{T}$ agar; the color of the aerial mycelium was light grayish yellow and thus it belongs to the Yellow color-series. Neither melanin nor other soluble pigments were formed on any agar media tested.

Physiclogical characteristics

The physiological characteristics are shown in Table 2. The strain contained cell walls of type I (LL-diaminopimelic acid). It is unusual
Fig. 2. Electron microphotograph of spores of strain No. C-19393. Bar indicates $1 \mu \mathrm{m}$.

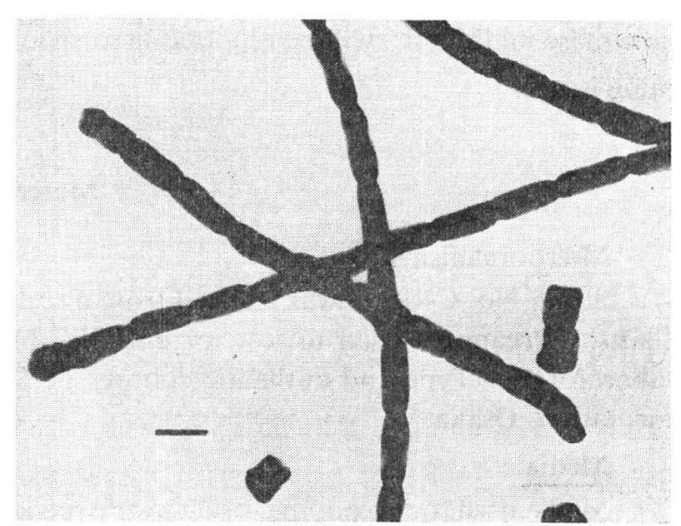


Table 1. Cultural characteristics of strain No. C-19393.

\begin{tabular}{|c|c|c|}
\hline Medium & Growth & Aerial mycelium* \\
\hline Sucrose-nitrate agar & moderate & moderate, white \\
\hline Glucose-asparagine agar & moderate & poor, white \\
\hline Glycerol-asparagine agar (ISP No. 5) & moderate & moderate, white \\
\hline Inorganic salts-starch agar (ISP No. 4) & moderate & poor, white \\
\hline Nutrient agar & poor & none \\
\hline Tyrosine agar & moderate & moderate, pastel yellow ( $2 \mathrm{db})$ \\
\hline Yeast-malt extract agar (ISP No. 2) & moderate & poor, parchment $\left(1 \frac{1}{2} \mathrm{db}\right)$ \\
\hline Oatmeal agar (ISP No. 3) & moderate & poor, white-parchment $\left(1 \frac{1}{2} \mathrm{db}\right)$ \\
\hline $\mathrm{T}$ agar & abundant & abundant, parchment $\left(1 \frac{1}{2} \mathrm{db}\right)$ \\
\hline
\end{tabular}

* Color determination with Color Harmony Manual. ${ }^{2)}$ Reverse color was colorless and soluble pigments were not produced on any media tested.

in growing over a lower temperature range than many actinomycetes; it grew at $4^{\circ} \mathrm{C}$ but not above $36^{\circ} \mathrm{C}$. Sporulation was most abundant at $21 \sim 24^{\circ} \mathrm{C}$. A distinctive feature in its utilization of carbon compounds was its inability to metabolize mannitol.

Identification

Analysis of the above results indicated that strain No. C-19393 is a member of the genus Streptomyces of the Yellow color-series with chains of RF-type smooth-surface spores and without melanoid pigment formation. It can thus be regarded as a species related to those listed in Table 17.43 by Pridham and Tresner in Bergey's Manual, 8th ed. ${ }^{10)}$ However, strain No. C-19393 is not identical with any species in that table, nor with those in the recent literature. It can be regarded as a species close to Streptomyces griseus in its gross cultural characteristics (grayish yellow color and powdery appearance) and morphology (formation of tufts). Although it has these typical characters of $S$. griseus, strain No. C-19393 differed in being unable to use D-mannitol and to grow at $37^{\circ} \mathrm{C}$, the optimum temperature for S. griseus. In addition, strain No. C-19393 grew at $4^{\circ} \mathrm{C}$. Examina-
Table 2. Physiological characteristics of strain No. C-19393.

\begin{tabular}{|c|c|}
\hline Test & Characteristic \\
\hline $\begin{array}{l}\text { Temperature } \\
\text { requirement }\end{array}$ & $\begin{array}{l}\text { growth: } 4 \sim 35^{\circ} \mathrm{C} \\
\text { (good sporulation at } \\
21 \sim 24^{\circ} \mathrm{C} \text { ) }\end{array}$ \\
\hline Gelatin & liquefied \\
\hline Starch & hydrolyzed \\
\hline Milk & $\begin{array}{l}\text { peptonized but not } \\
\text { coagulated }\end{array}$ \\
\hline Melanin pigment & not produced \\
\hline Cell wall type & I (containing LL-DAP) \\
\hline \multicolumn{2}{|l|}{$\begin{array}{l}\text { Utilization of carbon } \\
\text { compounds }\end{array}$} \\
\hline Glycerol & $H$ \\
\hline$i$-Inositol & \pm \\
\hline D-Mannitol & - \\
\hline D-Xylose & + \\
\hline L-Arabinoe & $H$ \\
\hline D-Glucose & $H$ \\
\hline D-Galactose & H \\
\hline D-Fructose & $H$ \\
\hline Maltose & + \\
\hline Sucrose & - \\
\hline Rhamnose & \# \\
\hline Raffinose & - \\
\hline Starch & $H$ \\
\hline
\end{tabular}

Symbols: H, efficient utilization; +, utilization; \pm , doubtful utilization; - , no utilization.

tion of 13 authentic cultures from the Institute for Fermentation, Osaka, including the type strain, ISP 5236 , for growth at different temperatures showed none able to grow at $6^{\circ} \mathrm{C}$ (data not shown). Accordingly, strain No. C-19393 was named Streptomyces griseus subsp. cryophilus. The type strain, 
No. C-19393, has been deposited in the Institute for Fermentation, Osaka, under accession number IFO 13886.

\section{Fermentation}

Preliminary studies on the fermentation conditions revealed that the combination of glucose and starch was a good carbon source and that soybean meal mixed with cotton-seed meal was a good nitrogen source. The addition of $\mathrm{CoCl}_{2}$ greatly stimulated production of the antibiotics (Fig. 3). The optimum concentration was between 0.3 and $20 \mu \mathrm{g} /$ ml. The effect of $\mathrm{CoCl}_{2}$ could be replaced by vitamin $\mathrm{B}_{12}$.

The fermentation was optimized from preliminary experiments and was carried out as follows: Strain No. C-19393 was grown on a slant of $\mathrm{T}$ agar for 1 week and the spores generated were added to $500 \mathrm{ml}$ of seed medium in a 2-liter Sakaguchi flask which was then shaken at $28^{\circ} \mathrm{C}$ for 2 days on a reciprocating shaker. The culture was transferred into 30 liters of the seed medium in a 50 -liter stainless steel fermentor. After cultivation at $28^{\circ} \mathrm{C}$ for 2 days with aeration (30 liters/min) and agitation (280 rpm), the culture was transferred into 1,200 liters of fermentation medium in a 2,000-liter stainless steel fermentor. The fermentor was operated at $30^{\circ} \mathrm{C}$ for 5 days with aeration (840 liters/min) and agitation (180 rpm).

Fig. 3. Effect of $\mathrm{CoCl}_{2}$ on the production of antibiotics.

Cultivation was carried out at $30^{\circ} \mathrm{C}$ for 5 days in fermentation media supplemented with various levels of $\mathrm{CoCl}_{2}$. Potency was measured as $\beta$ lactamase-inhibiting activity and is expressed relative to that in the medium which showed the maximum potency of 100 .

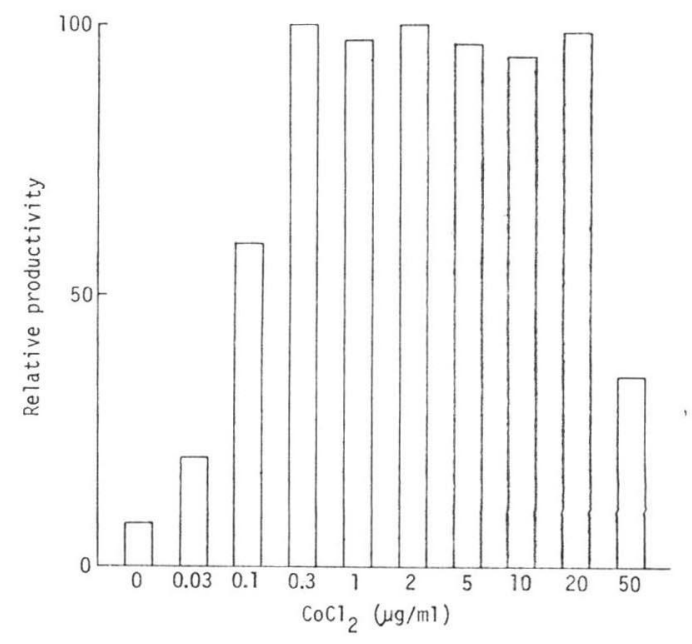

The antibiotics accumulated in the culture broth were isolated by chromatographic techniques, as described in the accompanying paper ${ }^{3}$.

\section{Antimicrobial Activities}

As seen in Table 3, both antibiotics exhibited antibacterial activities against a wide variety of Grampositive and Gram-negative bacteria. C-19393 $\mathrm{H}_{2}$ was $8 \sim 120$ times stronger than $\mathrm{C}-19393 \mathrm{~S}_{2}$. It inhibited all the tested bacteria at concentrations below $10 \mu \mathrm{g} / \mathrm{ml}$ and most at below $1 \mu \mathrm{g} / \mathrm{ml}$. On the other hand, no activities were observed against fungi and yeasts. The activity of $\mathrm{C}-19393 \mathrm{H}_{2}$ against clinically isolated bacteria resistant to $\beta$-lactam antibiotics was compared with that of cephaloridine. As shown in Table 4, C-19393 $\mathrm{H}_{2}$ was active against bacteria which were resistant to cephaloridine.

Several carbapenem antibiotics have been discovered as inhibitors of $\beta$-lactamases ${ }^{11 \sim 14)}$. C-19393 $\mathrm{S}_{2}$ and $\mathrm{H}_{2}$ also strongly inhibited several $\beta$-lactamases ${ }^{5)}$ and acted synergistically with ampicillin and cefotiam against bacteria resistant to $\beta$-lactam antibiotics due to production of $\beta$-lactamases. Some of the results are shown in Table 5. The potentiating effects were dramatic in several cases. For example, the addition of $0.5 \mu \mathrm{g} / \mathrm{ml}$ of $\mathrm{C}-19393 \mathrm{H}_{2}$ increased the activity of cefotiam against Proteus mirabilis TN 265 more than 1,000 times. The potentiating effects of C-19393 $\mathrm{S}_{2}$ and $\mathrm{H}_{2}$ varied with the organisms tested; the synergistic activity against $P$. vulgaris $\mathrm{GN} 4413$ was stronger with $\mathrm{C}-19393 \mathrm{~S}_{2}$ while that 
Table 3. Antimicrobial activities of $\mathrm{C}-19393 \mathrm{~S}_{2}$ and $\mathrm{H}_{2}$.

\begin{tabular}{l|c|c}
\hline \multirow{2}{*}{ Test organism } & Minimum inhibitory concentration, $\mu \mathrm{g} / \mathrm{ml}$ \\
\cline { 2 - 3 } & $\mathrm{C}-19393 \mathrm{~S}_{2}$ & $\mathrm{C}-19393 \mathrm{H}_{2}$ \\
\hline Staphylococcus aureus FDA 209P & 6.25 & 0.39 \\
Micrococcus luteus IFO 12708 & 25 & 0.39 \\
Bacillus subtilis IFO 3513 & 6.25 & 0.78 \\
Bacillus cereus IFO 3466 & $>25$ & 6.25 \\
Escherichia coli NIHJ JC 2 & 6.25 & 0.1 \\
Salmonella typhimurium IFO 12529 & 12.5 & 0.1 \\
Proteus vulgaris IFO 3988 & $>25$ & 3.13 \\
Proteus mirabilis ATCC 21100 & $>25$ & 1.56 \\
Enterobacter cloacae IFO 12937 & 25 & 0.78 \\
Serratia marcescens IFO 12648 & 12.5 & 0.2 \\
Klebsiella pneumoniae IFO 3318 & 12.5 & 0.1 \\
Alcaligenes faecalis IFO 13111 & $>25$ & 1.56 \\
Pseudomonas aeruginosa IFO 3080 & $>25$ & 6.25 \\
Comamonas terrigena IFO 13299 & 12.5 & 0.39 \\
Acinetobacter calcoaceticus IFO 12552 & $>25$ & 1.56 \\
Candida albicans IFO 0583 & $>25$ & $>25$ \\
Saccharomyces cerevisiae IFO 0209 & $>25$ & $>25$ \\
Aspergillus niger IFO 4066 & $>25$ & $>25$ \\
Penicillium chrysogenum IFO 4626 & $>25$ & $>25$ \\
\hline
\end{tabular}

Table 4. Antibacterial activities of $\mathrm{C}-19393 \mathrm{H}_{2}$ and cefotiam against clinical isolates resistant to $\beta$-lactam antibiotics.

\begin{tabular}{|c|c|c|}
\hline \multirow{2}{*}{ Test organism } & \multicolumn{2}{|c|}{ Minimum inhibitory concentration, $\mu \mathrm{g} / \mathrm{ml}$} \\
\hline & $\mathrm{C}-19393 \mathrm{H}_{2}$ & Cefotiam \\
\hline E. coli TN 649 (producer of PCase*) & 0.31 & 2.5 \\
\hline K. pneumoniae TN 1698 (high producer of PCase) & 1.25 & $>80$ \\
\hline S. marcescens TN 81 (high producer of CSase**) & 10 & $>80$ \\
\hline P. mirabilis TN 265 & 2.5 & $>80$ \\
\hline P. morganii GN 4738 (high producer of CSase) & 2.5 & $>80$ \\
\hline$P$. rettgeri TN 344 (producer of CSase) & 1.25 & $>80$ \\
\hline E. cloacae TN 587 (producer of CSase) & 0.63 & $>80$ \\
\hline Citrobacter freundii TN 515 (high producer of CSase) & 2.5 & $>80$ \\
\hline
\end{tabular}

* Penicillinase.

** Cephalosporinase.

against $P$. rettgeri TN 344 was stronger with $\mathrm{C}-19393 \mathrm{H}_{2}$.

\section{Discussion}

A number of streptomycetes have been reported to produce carbapenem antibiotics. S. griseus subsp. cryophilus subsp. nov. can be differentiated from these as follows: $S$. cattleya, the producer of thienamycin ${ }^{15)}$, is a Violet color-series streptomycete with spiral spore chains. S. olivaceus, S. flavogriseus and S. fulvissimus, the producers of olivanic acids ${ }^{11,18)}$ and epithienamycins ${ }^{17)}$, are Gray color-series streptomycetes. S. cremeus subsp. aurantilis, the producer of PS- $5^{18)}$, is a Red color-series streptomycete with RA spore chains. 
Table 5. Potentiation of antibacterial activities of ampicillin and cefotiam by $\mathrm{C}-19393 \mathrm{~S}_{2}$ and $\mathrm{H}_{2}$.

\begin{tabular}{|c|c|c|c|}
\hline \multirow{2}{*}{ Test organism, $10^{s} \mathrm{CFU} / \mathrm{ml}$} & \multirow{2}{*}{ Addition, $\mu \mathrm{g} / \mathrm{ml}$} & \multicolumn{2}{|c|}{ Minimum inhibitory concentration, $\mu \mathrm{g} / \mathrm{ml}$} \\
\hline & & Ampicillin & Cefotiam \\
\hline \multirow{5}{*}{$\begin{array}{l}\text { S. aureus } 1840 \\
\text { (producer of PCase) }\end{array}$} & None & 25 & 1.56 \\
\hline & \multirow{2}{*}{$\mathrm{S}_{2} * \quad 0.1$} & 6.25 & 0.78 \\
\hline & & 0.78 & 0.78 \\
\hline & $\mathrm{H}_{2} * * 0.1$ & 0.78 & 0.78 \\
\hline & 0.5 & 0.1 & 0.2 \\
\hline \multirow[t]{5}{*}{ E. coli TN 649} & None & $>800$ & 0.78 \\
\hline & & 800 & 0.39 \\
\hline & 0.5 & 50 & 0.2 \\
\hline & $\mathrm{H}_{2}$ & 25 & 0.1 \\
\hline & 0.5 & —*** & - \\
\hline \multirow{5}{*}{$\begin{array}{l}\text { K. pneumoniae IFO } 3512 * * * * \\
\text { (producer of PCase) }\end{array}$} & None & 200 & 0.2 \\
\hline & $\mathrm{S}_{2}$ & 0.39 & 0.1 \\
\hline & 0.5 & 0.39 & 0.1 \\
\hline & $\mathrm{H}_{2}$ & 0.2 & $\leq 0.02$ \\
\hline & 0.5 & - & - \\
\hline \multirow[t]{5}{*}{$P$. mirabilis $\mathrm{TN} 265$} & None & $>800$ & $>800$ \\
\hline & $\mathrm{S}_{2}$ & 12.5 & 3.13 \\
\hline & 0.5 & 6.25 & 1.56 \\
\hline & $\mathrm{H}_{2}$ & 100 & 25 \\
\hline & 0.5 & 1.56 & 0.78 \\
\hline \multirow{5}{*}{$\begin{array}{l}\text { P. vulgaris GN } 5297 \\
\text { (producer of CSase) }\end{array}$} & None & 200 & 100 \\
\hline & $\mathrm{S}_{2}$ & 3.13 & 3.13 \\
\hline & 0.5 & 6.25 & 3.13 \\
\hline & $\mathrm{H}_{2}$ & 3.13 & 3.13 \\
\hline & 0.5 & 1.56 & 1.56 \\
\hline \multirow{5}{*}{$\begin{array}{l}\text { P. vulgaris GN } 4413 \\
\text { (high producer of CSase) }\end{array}$} & None & $>800$ & $>800$ \\
\hline & $\mathrm{S}_{2} \quad 0.1$ & 12.5 & 6.25 \\
\hline & 0.5 & 12.5 & 3.13 \\
\hline & $\mathrm{H}_{2} \quad 0.1$ & 400 & 50 \\
\hline & 0.5 & 200 & 25 \\
\hline P. rettgeri $\mathrm{TN} 344$ & None & 200 & 200 \\
\hline & $\begin{array}{ll}\mathrm{S}_{2} & 0.1\end{array}$ & 200 & 200 \\
\hline & 0.5 & 100 & 50 \\
\hline & $\mathrm{H}_{2} \quad 0.1$ & 25 & 12.5 \\
\hline & 0.5 & 0.78 & 0.78 \\
\hline C. freundii TN 512 & None & 100 & 25 \\
\hline & $\begin{array}{ll}\mathrm{S}_{2} & 0.1\end{array}$ & 6.25 & 0.39 \\
\hline & 0.5 & 3.13 & 0.20 \\
\hline & $\mathrm{H}_{2} \quad 0.1$ & 1.56 & 0.78 \\
\hline & 0.5 & - & - \\
\hline
\end{tabular}

* C- $-19393 \mathrm{~S}_{2}$.

** C-19393 $\mathrm{H}_{2}$.

*** Test organism was inhibited by $0.5 \mu \mathrm{g} / \mathrm{ml} \mathrm{C}-19393 \mathrm{H}_{2}$.

**** Not a clinical isolate. 
Fermentative production of antibiotics C-19393 $\mathrm{S}_{2}$ and $\mathrm{H}_{2}$ was greatly stimulated by addition of $\mathrm{CoCl}_{2}$. This compound was also added to the fermentation media for the production of other carbapenem antibiotics, such as thienamycin ${ }^{15)}$ and olivanic acids ${ }^{13)}$, presumably based on the finding of similar effects. We do not know, however, through what mechanism(s) $\mathrm{CoCl}_{2}$ exerts its pronounced stimulatory effect.

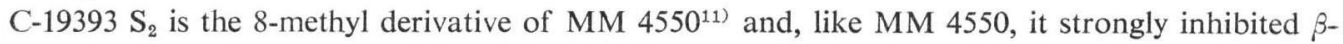
lactamases. The antibacterial activity of C-19393 $\mathrm{S}_{2}$ was rather low. In contrast, $\mathrm{C}-19393 \mathrm{H}_{2}$, which is the desulfonated derivative of C-19393 $\mathrm{S}_{2}$, exhibited very strong antibacterial activity against a wide variety of bacteria, including several clinical isolates resistant to $\beta$-lactam antibiotics. The marked difference between the antibacterial activities of $\mathrm{C}-19393 \mathrm{H}_{2}$ and $\mathrm{S}_{2}$ will be analyzed separately ${ }^{4)}$. C$19393 \mathrm{H}_{2}$ inhibited $\beta$-lactamases and acted synergistically in combination with ampicillin and cefotiam against $\beta$-lactamase-producing clinical isolates, as did C-19393 $\mathrm{S}_{2}$. The activities of C-19393 $\mathbf{S}_{2}$ and $\mathrm{H}_{2}$ as potentiators of ampicillin or cefotiam were variable, depending on the bacteria tested; C-19393 $\mathrm{S}_{2}$ showed a stronger effect than $\mathrm{C}-19393 \mathrm{H}_{2}$ for some bacteria and vice versa. Such variations are probably due to the difference between the two antibiotics in $\beta$-lactamase-inhibiting activity or in permeability.

The in vivo effectiveness of $\mathrm{C}-19393 \mathrm{~S}_{2}$ and $\mathrm{H}_{2}$ as antibacterial agents, either alone or as potentiators of classical penicillins and cephalosporins, is now being investigated.

\section{Acknowledgement}

We wish to thank Dr. E. OHMura for his interest and encouragement in this work. We are also indebted to Mrs. F. Kawashima, Messrs. K. Sasabe, O. Saga and Mrs. K. Kintaka for coordination.

\section{References}

1) Kitano, K.; K. Kintaka, S. Suzuki, K. Katamoto, K. Nara \& Y. Nakao: Screening of microorganisms capable of producing $\beta$-lactam antibiotics. J. Ferment. Technol. 53: 327 338, 1975

2) NozAKI, Y. \& A. IMADA: Analysis of mutants of Escherichia coli sensitive to $\beta$-lactam antibiotics: Mutants lacking penicillin-binding protein 1B. Presented at the Annual Meet. Agric. Chem. Soc. Japan, No. 2R-13 (p. 195), Tokyo, 1979

3) Harada, S.; S. Shinagawa, Y. Nozaki, M. Asai \& T. Kishi: C-19393 $\mathrm{S}_{2}$ and $\mathrm{H}_{2}$, new carbapenem antibiotics. II. Isolation and structures. J. Antibiotics 33: 1425 1430, 1980

4) Nozaki, Y.; F. Kawashima \& A. Imada: C-19393 $\mathrm{S}_{2}$ and $\mathrm{H}_{2}$, new carbapenem antibiotics. III. Mode of action. J. Antibiotics 34(2): 1981, in press.

5) Okonogi, K.; Y. Nozaki, A. Imada \& M. Kuno: C-19393 $\mathrm{S}_{2}$ and $\mathrm{H}_{2}$, new carbapenem antibiotics. IV. Inhibitory activities against $\beta$-lactamases. J. Antibiotics 34(2): 1981, in press

6) Shirling, E. B. \& D. Gottlieb: Methods for characterization of Streptomyces species. Intern. J. Syst. Bacteriol. 16: 313 340, 1966

7) Brown, A. G.; D. Butterworth, M. Cole, G. Hanscomb, J. D. Hood, C. Reading \& G. N. Rolinson: Naturally-occurring $\beta$-lactamase inhibitors with antibacterial activity. J. Antibiotics 29: 668 669, 1976

8) Nozaki, Y.; A. Imada \& M. Yoneda: SCE-963, a new potent cephalosporin with high affinity for penicillin-binding proteins 1 and 3 of Escherichia coli. Antimicr. Agents \& Chemoth. 15: 20 27, 1979

9) Container Corporation of America: Color Harmony Manual, 4th edition, Chicago, 1958

10) Pridham, T. G. \& H. D. Tresner: Genus I. Streptomyces Waksman and Henrici, 1943. 339, in Bergey's Manual of Determinative Bacteriology, 8th Ed. (R. E. Buchanan \& N. E. Gibbons, Ed.), pp. 747 845, The Williams \& Wilkins Co., Baltimore, 1974

11) Brown, A. G.; D. F. Corbett, A. J. Eglington \& T. T. Howarth: Structures of olivanic acid derivatives MM 4550 and MM 13902; two new fused $\beta$-lactams isolated from Streptomyces olivaceus. J. C. S., Chem. Comm. 1977: 523 525, 1977

12) Maeda, K.; S. Takahashi, M. Sezaki, K. Iinuma, H. Naganawa, S. Kondo, M. Ohno \& H. Umezawa: Isolation and structure of a $\beta$-lactamase inhibitor from Streptomyces. J. Antibiotics 30: 770 772, 1977

13) Butterworth, D.; M. Cole, G. Hanscomb \& G. N. Rolinson: Olivanic acids, a family of $\beta$-lactam antibiotics with $\beta$-lactamase inhibitory properties produced by Streptomyces species. I. Detection, properties and fermentation studies. J. Antibiotics 32: 287 294, 1979 
14) Okamura, K.; M. Sakamoto, Y. Fukagawa, T. Ishikura \& J. Lein: PS-5, a new $\beta$-lactam antibiotic. III. Synergistic effects and inhibitory activity against a $\beta$-lactamase. J. Antibiotics 32: 280 286, 1979

15) Kahan, J. S.; F. M. Kahan, R. Goegelman, S. A. Currie, M. Jackson, E. O. Stapley, T. W. Miller, A. K. Miller, D. Hendlin, S. Mochales, S. Hernandez, H. B. Woodruff \& J. Birnbaum: Thienamycin, a new $\beta$-lactam antibiotic. I. Discovery, taxonomy, isolation and physical properties. J. Antibiotics 32: $1 \sim 12,1979$

16) Umezawa, H.; S. Mitsuhashi, M. Hamada, S. Iyobe, S. Takahashi, R. Utahara, Y. Osato, S. Yamazaki, H. Ogawara \& K. Maeda: Two $\beta$-lactamase inhibitors produced by a Streptomyces. J. Antibiotics 26: $51 \sim 54,1973$

17) Stapley, E. O.; P. Cassidy, S. A. Currie, D. Daoust, R. Goegelman, S. Hernandez, M. Jackson, J. M. Mata, A. K. Miller, R. L. Monaghan, J. B. Tunac, S. B. Zimmerman \& D. Hendin: Epithienamycins: Biological studies of a new family of $\beta$-lactam antibiotics. Presented at the 17 th Intersci. Conf. Antimicr. Agents \& Chemoth., No. 80, New York, N. Y., 1977

18) Okamura, K.; S. Hirata, A. Koki, K. Hori, N. Shibamoto, Y. Okumura, M. Okabe, R. Okamoto, K. Kouno, Y. Fukagawa, Y. Shimauchi, T. Ishikura \& J. LeIn： PS-5, a new $\beta$-lactam antibiotic. I. Taxonomy of the producing organism, isolation and physicochemical properties. J. Antibiotics 32: 262 271, 1979 